\title{
M1T1 group A streptococcal pili promote epithelial colonization but diminish systemic virulence through neutrophil extracellular entrapment
}

\author{
Laura E. Crotty Alexander • Heather C. Maisey • Anjuli M. Timmer • \\ Suzan H. M. Rooijakkers • Richard L. Gallo • Maren von Köckritz-Blickwede • \\ Victor Nizet
}

Received: 14 September 2009 /Revised: 22 October 2009 / Accepted: 10 November 2009/Published online: 4 December 2009

(C) The Author(s) 2009. This article is published with open access at Springerlink.com

\begin{abstract}
Group A Streptococcus is a leading human pathogen associated with a diverse array of mucosal and systemic infections. Cell wall anchored pili were recently described in several species of pathogenic streptococci, and in the case of GAS, these surface appendages were demonstrated to facilitate epithelial cell adherence. Here we use targeted mutagenesis to evaluate the contribution of pilus expression to virulence of the globally disseminated M1T1 GAS clone, the leading agent of both GAS pharyngitis and severe invasive infections. We confirm that pilus expression promotes GAS adherence to pharyngeal cells, keratinocytes, and skin. However, in contrast to findings reported for group B streptococcal and pneumococcal pili, we observe that pilus expression reduces GAS
\end{abstract}

LE Crotty Alexander and HC Maisey contributed equally to this work.

L. E. Crotty Alexander ' H. C. Maisey · A. M. Timmer •

S. H. M. Rooijakkers $\cdot$ M. von Köckritz-Blickwede $\cdot$ V. Nizet $(\bowtie)$

Department of Pediatrics, University of California San Diego,

9500 Gilman Drive,

La Jolla, CA 92093, USA

e-mail: vnizet@ucsd.edu

L. E. Crotty Alexander

Department of Medicine,

Division of Pulmonary and Critical Care,

Massachusetts General Hospital,

55 Fruit Street,

Boston, MA 02114, USA

S. H. M. Rooijakkers

Medical Microbiology, University Medical Center Utrecht,

Heidelberglaan 100,

3584 CXUtrecht, Netherlands virulence in murine models of necrotizing fasciitis, pneumonia and sepsis, while decreasing GAS survival in human blood. Further analysis indicated the systemic virulence attenuation associated with pilus expression was not related to differences in phagocytic uptake, complement deposition or cathelicidin antimicrobial peptide sensitivity. Rather, GAS pili were found to induce neutrophil IL-8 production, promote neutrophil transcytosis of endothelial cells, and increase neutrophil release of DNA-based extracellular traps, ultimately promoting GAS entrapment and killing within these structures.

Keywords Group A Streptococcus · Pilus · Virulence factor . IL-8 $\cdot$ Neutrophil extracellular traps

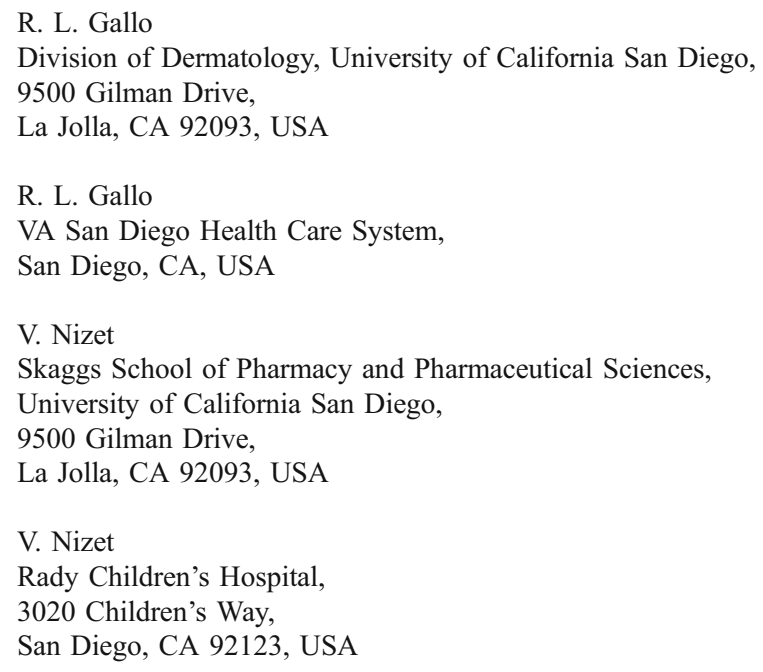




\section{Introduction}

Streptococcus pyogenes (group A Streptococcus (GAS)) is a leading human pathogen estimated to cause over 500,000 deaths each year globally, with disproportionate effects upon children, the elderly, and those living in developing countries $[1,2]$. While GAS can asymptomatically colonize the upper respiratory tract or skin of healthy individuals, it is also associated with a large spectrum of mucosal and invasive diseases, from simple pharyngitis or impetigo to the potentially life-threatening pneumonia, necrotizing fasciitis (NF) and toxic shock syndrome (TSS) [3]. A resurgence of severe GAS disease in recent decades has been mirrored by the emergence of a globally disseminated clone of the M1T1 serotype [4]. M1T1 strains are the most common cause of GAS pharyngitis and are strongly overrepresented in severe cases such as NF and TSS [5].

The ability of GAS to produce life-threatening infections even in previously healthy people reflects a diverse array of surface-associated and secreted virulence factors that together allow the bacterium to invade host cellular barriers, resist innate immune clearance, injure host tissues, and provoke harmful or dysregulated inflammatory responses [6, 7]. Remarkably, only in recent years was it recognized that major hair-like oligomeric surface organelles known as pili were present on the surface of Grampositive bacteria including the pathogenic streptococci GAS, group B Streptococcus (GBS), and Streptococcus pneumoniae [8]. Targeted mutagenesis coupled with tissue culture assays and murine infection models have indicated that both GBS and pneumococcal pili each contribute to disease pathogenesis, but in different manners. Both pilus structures promote cell adherence and invasion [9, 10]; however, while GBS pili aid in resistance to host antimicrobial peptide and neutrophil killing mechanisms [11], pneumococcal pili stimulate exaggerated proinflammatory responses including tumor necrosis factor- $\alpha$ (TNF- $\alpha)$ release [9].

The role of the GAS pilus structure in disease pathogenesis has not been studied extensively in vivo. GAS pili are encoded by a highly variable locus known as the fibronectin-binding, collagen-binding $\mathrm{T}$ antigen (FCT) region. In M1 strains, this pathogenicity island encodes RofA, a transcriptional regulator, Cpa, a collagen-binding protein [12], Spy0128, the pilus backbone subunit, Spy0125 and Spy0130, two pilus accessory proteins, and Spy0129 (SrtC1), a sortase enzyme that polymerizes the GAS pilus proteins via covalent linkage. GAS pilus assembly requires expression of Spy0128 and $\mathrm{SrtC1}$, but not the other genes. Interestingly, Spy0128 is now recognized to represent the classical Lancefield $\mathrm{T} 1$ antigen [13], a variable trypsin-resistant surface protein used for decades along with $\mathrm{M}$ protein for GAS typing schema based on serum recognition [14]. Deletion of Spy0128 suggests that GAS pili can contribute to biofilm formation [15] and bacterial aggregation in saliva [16], as well as adherence to human tonsil explants and some but not all human epithelial cell lines tested $[15,17]$. In the M53 serotype background, full-length GAS pili were not required for disease establishment in a humanized mouse model of impetigo [18].

In this study, we generate a targeted deletion of the Spy0128 major pilus backbone subunit in a representative isolate of the M1T1 GAS clone, originally isolated from a patient with NF and TSS, to study the role of pili in disease pathogenesis using several in vitro and in vivo model systems. While pili are seen to promote GAS colonization phenotypes, they are found to restrict invasive disease pathogenesis, in direct contrast to findings reported for GBS and pneumococcal pili. A novel association with neutrophil extracellular killing mechanisms may help explain this unexpected finding.

\section{Methods}

Bacterial strains, mutagenesis, and complementation

WT GAS M1T1 strain 5448 was isolated from a patient with NF and TSS [19]. GAS were propagated in ToddHewitt broth (THB) or on THB agar (THA; Difco, BD, Franklin Lakes, NJ, USA). Precise allelic replacement of the spy1028 gene was performed using an established methodology [20]. Briefly, $\sim 1,000$ bp of flanking DNA immediately upstream and downstream of the spy 1028 gene was amplified from the M1T1 chromosome by PCR using primers with $25 \mathrm{bp}$ extensions corresponding to the $5^{\prime}$ and $3^{\prime}$ end of the chloramphenicol acetyltransferase (cat) gene. The upstream and downstream PCR products were then joined with the cat gene (from plasmid pACYC1094) by fusion PCR, and the resultant amplicon, containing an inframe substitution of spy 1028 with cat, was subcloned into the temperature-sensitive suicide vector pHY304 to yield the knockout vector pSpy1028-KO. This vector was introduced into GAS M1T1 strain 5448 by electroporation and single and double crossover events identified by differential temperature and antibiotic sensitivity, using $5 \mu \mathrm{g} / \mathrm{ml}$ erythromycin (Erm) and $2 \mu \mathrm{g} / \mathrm{ml}$ chloramphenicol $(\mathrm{Cm})$ for selection. The isogenic mutant $5448 \Delta$ Pil was confirmed unambiguously by PCR and sequence analysis to contain a precise chromosomal replacement of spy 1028 with cat. For complementation analysis, the full-length spy0128 gene was amplified from the GAS M1T1 5448 genome, subcloned into the streptococcal expression vector pDCerm [20], and introduced into the 5448 $\Delta$ Pil mutant using Erm selection; an empty vector control strain was 
likewise generated. WT, mutant and complemented GAS strains exhibited equivalent growth kinetics in THB and RPMI-1640 media used in our tissue culture assays (data not shown).

Detection of pilus expression via immunofluorescent microscopy

Logarithmic-phase GAS were plated on Polysine microscope slides (Eerie Scientific) and fixed with 3\% paraformaldehyde (PFA). Slides were blocked with $3 \%$ bovine serum albumin (BSA) in PBS containing 0.05\% Tween-20 (blocking buffer) overnight at $4{ }^{\circ} \mathrm{C}$ in a humidified chamber. Slides were incubated with goat serum diluted 1:200 in blocking buffer, followed by incubation with primary rabbit antisera against the GAS T1 antigen, i.e., Spy1028 (obtained from Centers for Disease Control Streptococcal Laboratory, Atlanta, GA), diluted 1:1,000 in blocking buffer. The slides were then incubated with a secondary fluorescein isothiocyanate (FITC)-conjugated goat antirabbit $\operatorname{IgG}$ diluted 1:200 in blocking buffer. Mounted samples were viewed simultaneously with a $\times 60 / 1.42$ PlanApo objective after laser excitation at $488 \mathrm{~nm}$ and differential interference contrast using a spectral deconvolution confocal microscope (Olympus FV1000).

\section{Epithelial cell adherence assays}

Bacterial adherence to epithelial cells was determined as previously described [21]. Briefly, human pharyngeal epithelial cells (HEp-2) and skin keratinocytes (HaCaT) obtained from ATCC were propagated as monolayers in RPMI-1640+10\% fetal bovine serum (FBS), $2 \mathrm{mM} \mathrm{L-}$ glutamine, and $100 \mu \mathrm{M}$ nonessential amino acids at $37^{\circ} \mathrm{C}+$ $5 \% \mathrm{CO} 2$. For adherence assays, cells were plated at $2 \times 10^{5}$ cells/well in a tissue culture-treated 24 -well plate and incubated at $37^{\circ} \mathrm{C}$ overnight. Then $2 \times 10^{6}$ colony forming units (CFU) of logarithmic phase GAS (multiplicity of infection $=\mathrm{MOI}=10: 1)$ in fresh RPMI-1640 $+2 \%$ FBS were added to each well. The plate was centrifuged at 1600 RPM for $5 \mathrm{~min}$, then incubated at $37^{\circ} \mathrm{C}+5 \% \mathrm{CO} 2$ for $30 \mathrm{~min}$. Monolayers were washed with PBS to remove unattached bacteria, and $100 \mu \mathrm{l}$ of trypsin and $400 \mu \mathrm{l}$ of $0.025 \%$ Triton-X 100 were added to each well to facilitate cell detachment and lysis. Dilutions were plated on THB at $37^{\circ} \mathrm{C}$ overnight for enumeration of CFU.

\section{Skin adherence assay}

Eight-week-old female CD-1 mice (Charles River Laboratories, CA) were shaved and treated with $\mathrm{Nair}^{\circledR}$ (Church \& Dwight Co., Inc.) $24 \mathrm{~h}$ prior to infection. Logarithmic phase WT and $\triangle$ Pil mutant GAS were mixed 1:1 in PBS and
$10 \mu \mathrm{L}$ drops containing $1 \times 10^{6}$ total CFU plated on THA. Six-mm skin biopsy punches (Acuderm Inc.) were used to cut out disks of agar. Mice were sedated with ketamine/ xylazine intraperitoneally (i.p.). Agar disks were placed onto mouse skin for $1 \mathrm{~h}$ to allow bacterial adherence; control agar disks were added to $2 \mathrm{~mL}$ Micro-tubes (Sarstedt) on ice. Skin around the periphery of the agar disks was marked and agar disks gently lifted off and discarded. Skin within the marked perimeter was harvested using 8-mm skin biopsy punches and placed in $2 \mathrm{~mL}$ Micro-tubes containing $1 \mathrm{~mL}$ of PBS on ice. Tubes containing skin were placed in the Mini Bead Beater (Biospec Products, Inc.) and gently shaken on "wash" setting for $1 \mathrm{~min}$, supernatant was discarded, and $1 \mathrm{~mL}$ of fresh PBS was added. Skin was washed again for $1 \mathrm{~min}$, supernatant was discarded, and $1 \mathrm{~mL}$ of PBS with $1 \mathrm{~mm}$ Zirconia/Silica beads (Biospec Products, Inc.) was added to these tubes and control agar tubes. Skin and agar controls were homogenized for $2 \mathrm{~min}$, serially diluted, and replica plated on THA (for enumeration of all bacteria) and THA+ $2 \mu \mathrm{g} / \mathrm{mL} \mathrm{Cm}$ (for enumeration of $\Delta$ Pil alone).

\section{Animal infection models}

Eight- to ten-week-old female CD-1 mice were used for all experiments. Necrotizing subcutaneous infection was studied using a well-established model [21-23]. Briefly, logarithmic phase GAS were diluted 1:1 with sterile Cytodex beads (Sigma). Eight- to ten-week-old female CD-1 mice were shaved and $\mathrm{Nair}^{\circledR}$ applied $24 \mathrm{~h}$ prior to infection. Mice were injected subcutaneously in the left flank with $5 \times 10^{7}$ WT or $\Delta$ Pil + Pil complemented mutant GAS and simultaneously in the right flank with an equivalent inoculum of the isogenic $\Delta$ Pil mutant, allowing each mouse $(N=8)$ to serve as its own control. Developing lesion sizes were measured daily, and on $\mathrm{d} 4$ mice were euthanized, skin lesions excised, homogenized, and serially diluted for plating on THA and enumeration of CFU. Pneumonia was modeled by introducing $1 \times 10^{8} \mathrm{CFU}$ WT or isogenic $\triangle$ Pil mutant GAS into the left nare of mice held in the upright position. At 24 or $48 \mathrm{~h}$, mice were euthanized with inhaled $\mathrm{CO}_{2}$. The right lung was homogenized, serially diluted, and plated on THA for enumeration of total CFU. The left lung was inflated with 4\% PFA for $5 \mathrm{~min}$, resected, and placed in PFA for histology. Hematoxylin-eosin-stained lung sections were evaluated under light microscopy at $\times 10, \times 40$, and $\times 100$ using a Zeiss Axiolab microscope. Systemic sepsis was modeled by injecting $2 \times 10^{8} \mathrm{CFU}$ logarithmic phase WT or isogenic $\Delta$ Pil mutant GAS in $100 \mu \mathrm{L}$ of PBS via tail vein; mice were then monitored twice daily for mortality $(N=11$ or 12 animals per group total from two separate experiments). 
Whole blood, macrophage, and antimicrobial peptide killing assays

For whole blood killing assays, a phlebotomy sample was obtained from a healthy human volunteer and $300 \mu \mathrm{L}$ placed in each 2-mL siliconized tube (Fisher Scientific). Next, $100 \mu \mathrm{L}$ of logarithmic phase GAS was added to reach a final concentration of $1 \times 10^{4} \mathrm{CFU} / \mathrm{mL}$. Tubes were incubated on a tube rotator at $37^{\circ} \mathrm{C}$. At $2 \mathrm{~h}$, blood was serially diluted and plated on THA for enumeration of CFU. For J774 murine macrophage killing assays, cells were plated at $7.5 \times 10^{5}$ cells/well in RPMI- $1640+2 \%$ FBS in a 24-well plate and incubated at $37^{\circ} \mathrm{C}+5 \% \quad \mathrm{CO}_{2}$ overnight. Then $7 \times 10^{6} \mathrm{CFU}$ of logarithmic phase GAS were added to each well and the plates were incubated for 30 min at $37^{\circ} \mathrm{C}+5 \% \mathrm{CO}_{2}$. Cells were rinsed with $\mathrm{PBS}$, detached and lysed with $0.025 \%$ Triton X-100, serially diluted, and plated on THA for enumeration of total cellassociated CFU. For cathelicidin antimicrobial peptide killing assays, GAS were grown to logarithmic phase, brought up at $1 \times 10^{5} \mathrm{CFU} / \mathrm{mL}$ in $70 \% \mathrm{DMEM}+10 \% \mathrm{FBS}+$ $20 \% \mathrm{THB}$, and $90 \mu \mathrm{L}$ was added to $10 \mu \mathrm{L}$ of varying concentrations of human (LL-37) or mouse (CRAMP) cathelicidin in triplicate wells in a 96-well plate, then incubated for $24 \mathrm{~h}$ at $37^{\circ} \mathrm{C}$. Bacteria were plated on THA to determine the MIC for each peptide.

\section{Complement deposition}

Human serum was isolated from whole blood by coagulation in glass serum tubes (BD Biosciences) and stored at $-80^{\circ} \mathrm{C}$. Normal human serum (nhs) was generated by pooling sera from six different donors. To inactivate complement, nhs was heat-inactivated at $56^{\circ} \mathrm{C}$ for $30 \mathrm{~min}$. GAS were grown to logarithmic phase and washed with HEPES-buffered saline containing $5 \mathrm{mM} \mathrm{CaCl}_{2}$ and $2.5 \mathrm{mM} \mathrm{MgCl} 2\left(\mathrm{HBS}^{++}\right)+1 \%$ BSA ( $\left.\mathrm{HBS}^{++}-\mathrm{BSA}\right)$. Bacteria were diluted $\times 200$ and incubated with nhs at $0 \%, 2 \%$, $5 \%$, and $10 \%$ for $20 \mathrm{~min}$ at $37^{\circ} \mathrm{C}$ in a fast shaker. Bacteria were washed and incubated with FITC-conjugated antihuman $\mathrm{C} 3$ antibodies (Protos Immunoresearch) on ice for $30 \mathrm{~min}$. Washed bacteria were taken up in PBS and analyzed on BD FACSCalibur flow cytometer, using BD CellQuest Pro, and data were analyzed with FlowJo (Tree Star, Inc.). Fluorescent mean, median, and geometric mean were obtained from all samples.

Neutrophil endothelial transcytosis assays

Human brain endothelial cells were propagated as monolayers in RPMI-1640+10\% FBS and human lung endothelial cells (kind gift of Dr. Jeffrey Esko) were propagated as monolayers in DMEM (low glucose $\times 1$; Mediatech) $+20 \%$
FBS $+1 \%$ nonessential amino acids $+50 \mu \mathrm{g} / \mathrm{mL}$ heparin at $37^{\circ} \mathrm{C}+5 \% \mathrm{CO} 2$. Transwells (Costar) were placed inside tissue culture-treated 24 -well plates, with $500 \mu \mathrm{L}$ of media in the lower chambers. Cells were plated at $5 \times 10^{5}$ cells/ upper chamber in $150 \mu \mathrm{L}$ of media and incubated at $37^{\circ} \mathrm{C}+5 \% \mathrm{CO} 2$ until confluent monolayers formed. Next, $1 \times 10^{6} \mathrm{CFU}$ of logarithmic phase WT, $\Delta$ Pil + Pil complemented mutant, or $\Delta$ Pil mutant were added to each lower chamber and $1 \times 10^{6}$ fresh human neutrophils were added to each upper chamber. At indicated time-points, the media in lower chambers was gently agitated, $30-\mu \mathrm{L}$ samples removed, and the total number of neutrophils migrating to the lower chamber quantified with a hemocytometer under light microscopy.

Neutrophil IL-8 release and phagocytosis assays

To measure neutrophil interleukin- 8 (IL-8) release, $1 \times 10^{5}$ human neutrophils were infected with $1 \times 10^{4} \mathrm{CFU}$ of logarithmic phase GAS. At $3 \mathrm{~h}, 200 \mu \mathrm{L}$ of media was removed and spun at 1,400 RPM, and the supernatant frozen at $-20^{\circ} \mathrm{C}$. Quantitative ELISA for IL-8 was performed using an IL-8 Quantikine kit (R\&D Systems) according to the manufacturer's instructions, using samples thawed on ice and diluted 1:4 in ELISA buffer. To assess neutrophil phagocytosis, GAS were labeled with FITC through a modified protocol derived from Goldmann et al., 2004 [24]. Logarithmic-phase GAS were concentrated in PBS to $\mathrm{OD}_{600}$ of 1.0 , FITC was added to a final concentration of $0.2 \mathrm{mg} / \mathrm{mL}$, and samples incubated for 30 min, on ice, in the dark. Bacteria were washed with PBS until the supernatant was clear, then $1 \times 10^{6} \mathrm{CFU}$ were added to $1 \times 10^{5}$ neutrophils (MOI 10:1) in RPMI-1640+ $2 \%$ FBS. Samples were incubated for $60 \mathrm{~min}$ at $37^{\circ} \mathrm{C}$. Trypan blue was added for a final concentration of $0.5 \%$ to quench extracellular fluorescence. Samples were rinsed with PBS and then run on BD FACSCalibur flow cytometer, using BD CellQuest Pro, and data was analyzed with FlowJo (Tree Star, Inc.). Fluorescent mean, median, and geometric mean were obtained on all samples.

Neutrophil extracellular trap assays

To assess neutrophil extracellular trap (NET) induction, coverslips (1/2 oz, $12 \mathrm{~mm}$; Fisher) were coated with PolyD-lysine (Sigma) and placed in 24-well ultra low attachment surface plates (Costar) with 500- $\mu \mathrm{L}$ RPMI- $1640+2 \%$ heatinactivated human serum. Human neutrophils were plated at $5 \times 10^{5}$ per well, infected with $5 \times 10^{4}$ CFU logarithmicphase GAS, and spun at 1,600 RPM for $10 \mathrm{~min}$ prior to incubation at $37^{\circ} \mathrm{C}+5 \% \mathrm{CO}_{2}$ for $20 \mathrm{~min}$. PFA was added to final concentration of $4 \%$ and coverslips were inverted into ProLong ${ }^{\circledR}$ Gold with DAPI (Invitrogen). NETs were 
visualized and quantified per visual field using a $\times 40 / 0.65$ Achroplan objective with a Zeiss Axiolab fluorescent microscope. For NET adherence and killing assays, neutrophils were incubated with $25 \mathrm{nM}$ phorbol myristate acetate (PMA) for $4 \mathrm{~h}$ to maximally induce NETs and eliminate phagocytosis. NETs were infected with GAS and spun at 1,600 RPM for $10 \mathrm{~min}$. To quantify adherence, NETs and bacteria were incubated at $37^{\circ} \mathrm{C}+5 \% \mathrm{CO}_{2}$ for 5 min. NETs were gently rinsed with PBS, then harvested with $0.025 \%$ Triton X-100, serially diluted, and plated on THA for enumeration of total NET-associated CFU. For killing assays, NETs and bacteria were incubated at $37^{\circ} \mathrm{C}+$ $5 \% \mathrm{CO}_{2}$ for $20 \mathrm{~min}$. NETs and bacteria were harvested with $0.025 \%$ Triton X-100, serially diluted, and plated on THA for enumeration of total cell-associated CFU. In both adherence and killing assays, at the end of their respective incubations, two wells of each condition were treated with LIVE/DEAD BacLight staining (Molecular Probes), fixed with 1\% PMA, mounted onto glass slides using ProLong ${ }^{\circledR}$ Gold with DAPI and immediately visualized under fluorescent microscopy.

\section{Statistical analysis}

Differences in bacterial counts were evaluated by Student's $t$ test. Significance was determined as $P<0.05$. Survival curves were evaluated by the Wilcoxon's rank-sum test.

\section{Assurances}

Human blood collection and neutrophil isolation were approved by the University of California San Diego (UCSD) Human Research Protections Program. Animal studies were approved by the UCSD Institutional Animal Use and Care Committee.

\section{Results}

Mutagenesis and complementation of pilus expression in GAS strain M1 5448

To explore the functional role of pili in the pathogenesis of invasive M1T1 GAS disease, a knockout mutant ( $\Delta$ Pil) of strain 5448 was generated by precise allelic exchange mutagenesis of spy0128, then complemented by return of the spy0128 gene on an expression plasmid. To confirm functional changes in GAS pilus expression, we performed immunofluorescent labeling against Spy0128. Whereas surface pili were observed in the WT GAS parent strain and the complemented mutant, no pili were detected on the surface of the $\Delta$ Pil mutant (Fig. 1a).
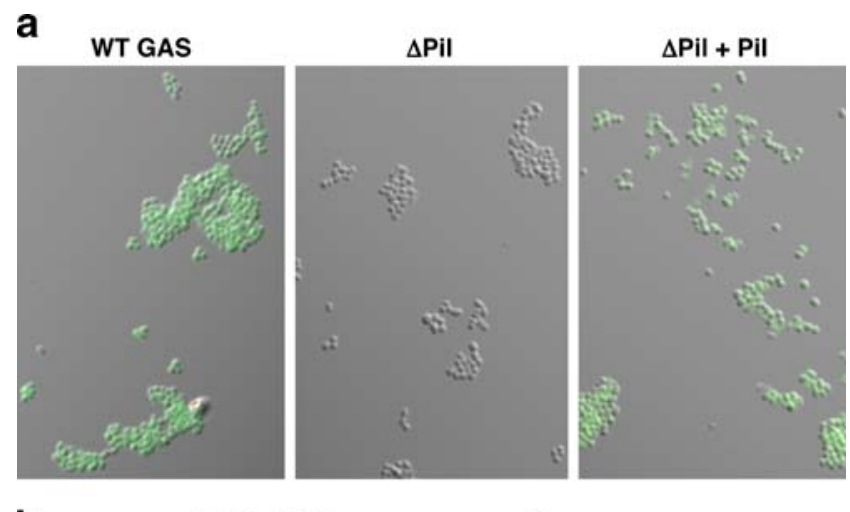

b
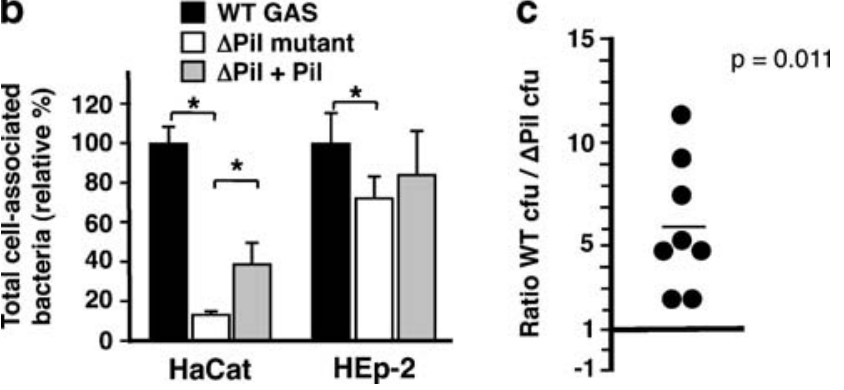

Fig. 1 Targeted deletion of the spy0128 gene eliminates pilus expression and reduces GAS adherence to human epithelial cells and mouse skin. a Green fluorescent immunostaining with anti-T1 antigen (Spy0218) antisera is positive for WT GAS, negative for the isogenic $\Delta$ Pil mutant, and restored in the $\Delta$ Pil + Pil complemented strain. b GAS WT and $\Delta$ Pil + Pil complemented strains are more adherent to keratinocytes and epithelial cells compared with the $\Delta$ Pil mutant, $* P<0.05$. c GAS WT outcompetes $\Delta$ Pil in adherence to mouse skin; circles represent the ratio of GAS WT CFU to $\triangle$ Pil mutant CFU recovered for individual skin lesions, bar represents the mean. In vivo experiments were repeated three times, representative experiment shown

Pili contribute to GAS M1T1 epithelial cell adherence in vitro and skin adherence in vivo

Adherence phenotypes were assessed in cell lines representative of the two principal sites of GAS colonization. Compared to the WT GAS parent strain, the isogenic $\Delta$ Pil mutant showed an $87 \%$ reduction in adherence to $\mathrm{HaCaT}$ human keratinocytes $(P<0.001$; Fig. 1b), a defect that was partially restored in the complemented mutant $(P<0.005)$, and a $28 \%$ reduction in adherence to HEp-2 human pharyngeal epithelial cells $(P<0.05)$; although the observed partial complementation $(\sim 12 \%)$ of the latter defect did not reach statistical significance. To assess the role of pili in GAS adherence to intact skin, a competition experiment was performed in which a $1: 1$ mixture of WT and $\Delta$ Pil mutant GAS was inoculated on mouse skin for $1 \mathrm{~h}$ before harvesting and bacterial enumeration. Control sample mixtures were plated to confirm the initial inoculum. WT GAS outcompeted the isogenic $\Delta$ Pil mutant, as demonstrated by a ratio of greater than 1 in all samples. The 
median ratio of WT: $\triangle$ Pil bacteria recovered was $>6: 1$ in the excised skin samples $(P<0.02$; Fig. 1c).

Pilus expression blunts M1T1 GAS virulence in three different murine infection models

The contribution of pilus expression to GAS invasive disease pathogenesis was tested in three different model systems of infection, providing surprising but internally consistent results. First a subcutaneous injection model was used, in which GAS M1T1 produces necrotizing lesions or ulcers with histopathologic features resembling human NF. Compared to the WT GAS parent strain, the isogenic $\Delta$ Pil mutant produced significantly larger lesions by $\mathrm{d} 2$ and $\mathrm{d} 3$ post-infection $(P<0.02$; Fig. 2a; representative mouse shown in Fig. $2 \mathrm{c})$, while the complemented mutant $(\Delta \mathrm{Pil}+$ Pil) mutant had significantly smaller lesions on $\mathrm{d} 3$ postinfection than $\triangle$ Pil harboring an empty vector control $(P<$ 0.02 ; Fig. 2b). Next, GAS pneumonia was established in mice by intranasal inoculation and lungs harvested at 24 or $48 \mathrm{~h}$. We found significantly more bacteria were recovered from lungs of mice infected with the GAS $\Delta$ Pil mutant than the WT parent strain at either time point $(P<0.04$; Fig. 3a). By $24 \mathrm{~h}$, histopathology reflected the increased bacterial burden in the lungs of $\Delta$ Pil-infected mice, and by $48 \mathrm{~h}$, markedly more severe pneumonia with dense neutrophilic infiltration was evident in the $\Delta$ Pil-infected mice vs. the WT GAS-infected mice (Fig. 3b). Finally, we modeled GAS sepsis by injecting the bacteria intravenously and monitoring mortality. In this study, the $\triangle$ Pil mutant GAS demonstrated more rapid kinetics of lethality (50\% dead by $72 \mathrm{~h}$ vs $96 \mathrm{~h}$ for the WT strain; $100 \%$ mortality in $96 \mathrm{~h}$ vs. $144 \mathrm{~h}$ for the WT strain, $\mathrm{P}=0.002$, Fig. $3 \mathrm{c}$ ). Thus in three distinct models of invasive M1T1 GAS infection, we observed pilus expression to diminish virulence potential, a finding opposite to those reported for the GBS or pneumococcal pili in systemic mouse infection models.
Pilus expression increases GAS susceptibility to human whole blood killing

To extend our animal observations to interactions with components of the human innate immune system, we assessed the contribution of pilus expression to M1T1 GAS survival in freshly drawn human blood. Consistent with diminished systemic virulence in the mouse studies, we found the $\Delta$ Pil mutant had a $50 \%$ increase in blood survival compared with WT GAS parent strain $(P<0.001)$; survival was reduced toward WT levels in the $\triangle$ Pil+Pil complemented mutant $(P<0.02$; Fig. 4a). However, in contrast to findings reported for the GBS pili [11], GAS pilus expression did not alter the bacterium's susceptibility to killing by the human cathelicidin antimicrobial peptide LL-37 (MIC $=32 \mu \mathrm{M}$ for both WT and $\Delta$ Pil mutant) nor the murine cathelicidin antimicrobial peptide mCRAMP (MIC $=16 \mu \mathrm{M}$ for both strains). No difference was observed in WT vs. $\Delta$ Pil mutant GAS susceptibility to killing by $\mathrm{J} 774$ murine macrophages (Fig. 4b), and similar degrees of complement $\mathrm{C} 3 \mathrm{~b}$ deposition were measured on the surface of the WT and $\Delta$ Pil mutant bacteria after incubation in human serum (Fig. 4c). Consistent with equivalent levels of C3b-mediated opsonization, human neutrophil phagocytotic uptake of FITC-labeled WT, $\Delta$ Pil mutant and $\Delta$ Pil + Pil complemented mutant bacteria was similar as assessed by flow cytometry (Fig. 4d). Together these data indicate that the attenuating effect of pilus expression on M1T1 GAS virulence in the animal infection models or human blood killing studies was not linked to increased neutrophil opsonophagocytosis.

GAS pilus expression stimulates neutrophil IL-8 production and endothelial transcytosis

An important property reported for pneumococcal pili is the induction of increased levels of host pro-inflammatory

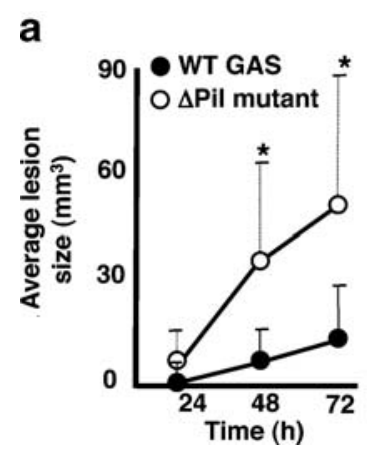

Fig. 2 Deletion of GAS pilus expression increases virulence in a mouse model of necrotizing fasciitis. a Subcutaneous infection with the $\Delta$ Pil mutant generates larger skin lesions compared with GAS WT at $48 \mathrm{~h}(P=0.014)$ and $72 \mathrm{~h}(P=0.013)$; representative mouse from

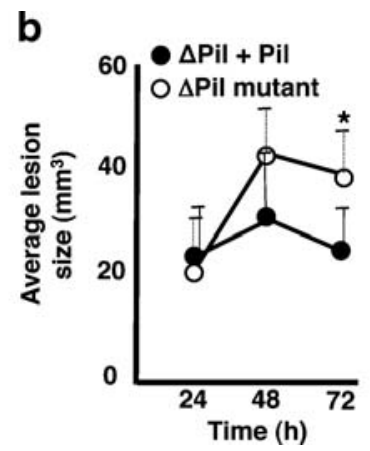

C

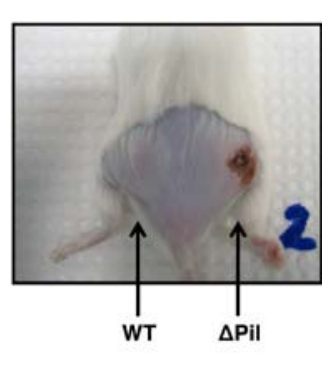

these experiments shown in c. b The $\Delta \mathrm{Pil}+\mathrm{Pil}$ complemented mutant produces smaller skin lesions than the $\Delta$ Pil mutant at $72 \mathrm{~h}(P=0.011)$. Eight mice were used per group and all experiments were repeated three times with similar results 

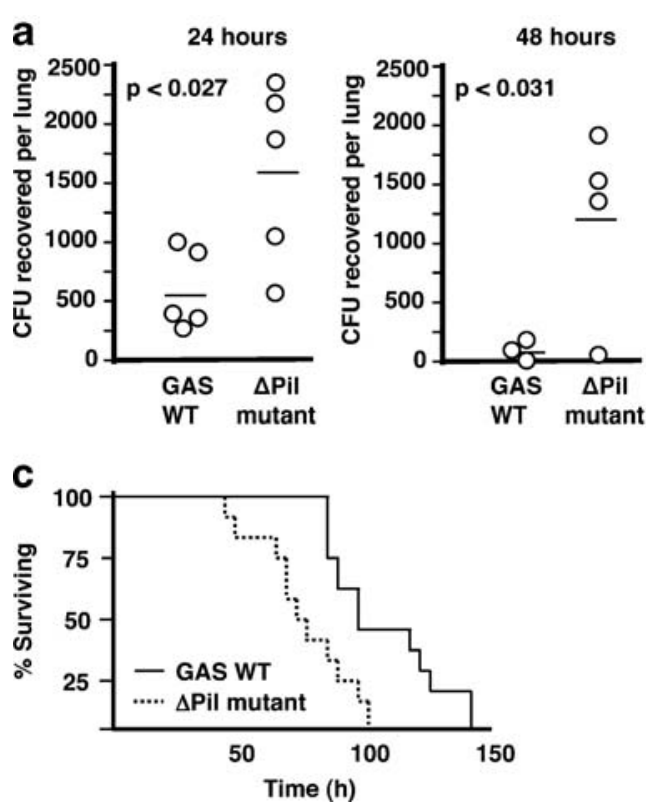

Fig. 3 Deletion of GAS pilus expression increases virulence in mouse models of pneumonia and sepsis. a Mice infected intranasally with GAS WT had significantly fewer bacteria in their lungs at 24 and $48 \mathrm{~h}$. b Representative hematoxylin-eosin-staining of lung sections demonstrates more histopathological damage in $\Delta$ Pil lungs vs. WTinfected lungs at 24 and $48 \mathrm{~h}$. c Mice infected intravenously with the b

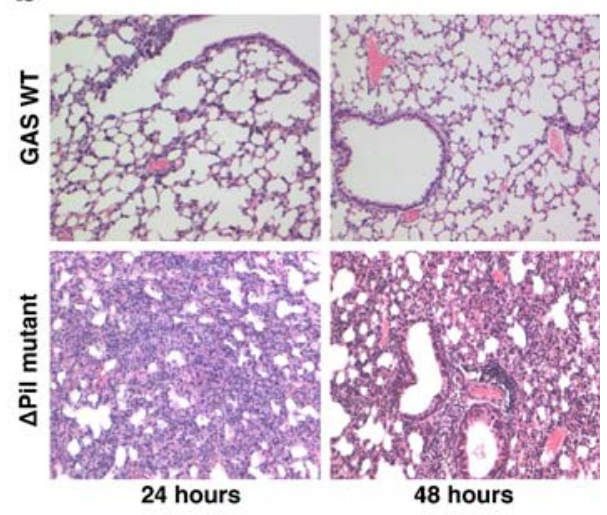

$\Delta$ Pil mutant died an average of $72 \mathrm{~h}$ after infection compared with $96 \mathrm{~h}$ after infection for WT-infected mice $(P=0.002)$. The survival curve was generated from pooling data from two experiments. At least three mice were used per group and all experiments were repeated three times
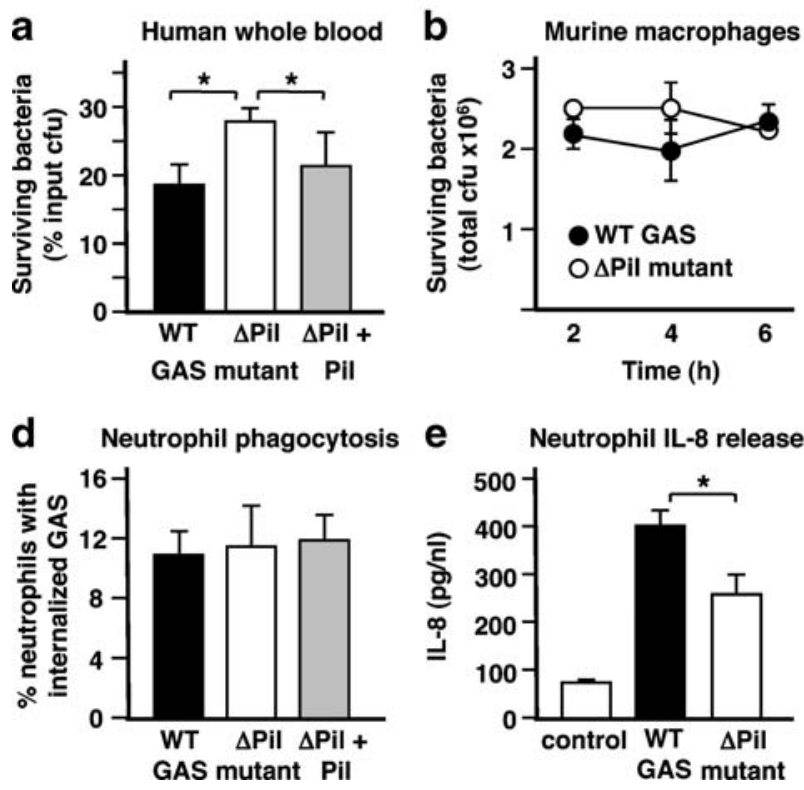
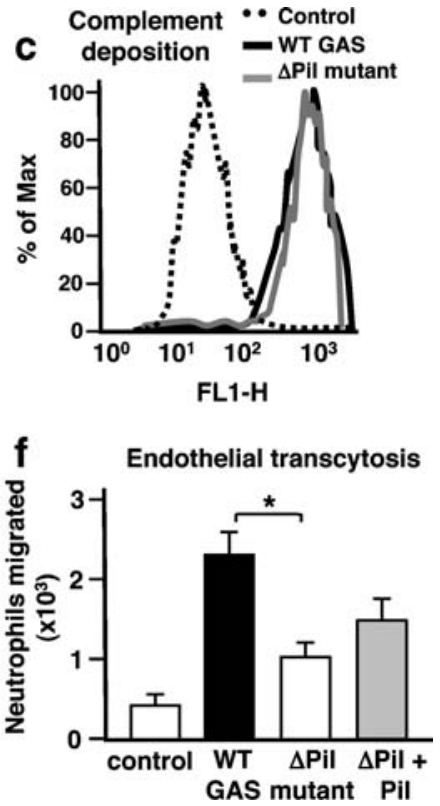

Fig. 4 Pilus expression in GAS leads to increased susceptibility to whole blood killing and stimulates increased IL-8 release and transendothelial migration by human neutrophils. a The $\Delta$ Pil mutant had increased survival in human whole blood compared with WT GAS $(P=0.0001)$ or the $\Delta$ Pil + Pil complemented mutant $(P=0.016)$. b No difference in survival between piliated and non-piliated GAS strains in a macrophage killing assay. c No difference in surface deposition of complement component $\mathrm{C} 3 \mathrm{~b}$ in piliated vs. non-piliated
GAS. d Human neutrophils phagocytose FITC labeled GAS WT, $\Delta$ Pil mutant, and $\Delta$ Pil + Pil complemented mutant strains with equivalent efficiency. e Increased secretion of IL- 8 by neutrophils exposed to WT GAS vs. the $\Delta$ Pil mutant $(P=0.009)$. f Increased migration of neutrophils through an endothelial monolayer in response to WT GAS compared with the isogenic $\Delta$ Pil mutant $(P=0.03)$. All experiments were performed in triplicate and were repeated three times; representative experiment shown 
cytokine expression [9]. IL-8 is a multifunctional human innate defense protein with a key role in the recruitment and activation of neutrophils [25]. IL-8 is produced in large amounts by neutrophils upon detecting bacteria $[26,27]$ and acts in an autocrine fashion to stimulate bactericidal activities such as oxidative burst and release of granule enzymes $[28,29]$. To evaluate the effect of M1T1 GAS pili on IL-8 production, freshly isolated human neutrophils were exposed to GAS and IL-8 quantified by ELISA. Neutrophils infected with the WT parent strain released $\sim 35 \%$ more IL-8 than those infected with the isogenic $\Delta$ Pil mutant $(P<0.01$; Fig. 4e). An established Transwell assay was utilized to examine how the presence of pili influenced human neutrophil endothelial transmigration toward the pathogen. Human microvascular endothelial cells were grown to confluence on a Transwell membrane, the lower chambers inoculated with WT, $\Delta$ Pil mutant or $\Delta$ Pil + Pil complemented mutant M1T1 GAS, and freshly isolated human neutrophils added to the upper chambers. As shown in Fig. 4f, the $\Delta$ Pil mutant GAS elicited the transmigration of less than half as many neutrophils as the WT parent strain $(P<0.04)$; genetic complementation of the mutant partially reversed the observed phenotype with a third more neutrophils transmigrating compared with the $\Delta$ Pil mutant.

GAS pilus expression increases NET production and the entrapment of GAS within these structures

Release of extracellular DNA-based antimicrobial traps has recently been discovered as a new paradigm in the innate immune function of neutrophils [30,31]. This process is morphologically distinct from other classical cell death processes including apoptosis and necrosis, and has been dubbed "NETosis" [32]. Binding of many species of bacteria and fungi within the DNA backbone has been demonstrated, and NETs contain cationic histones, granule proteases, and antimicrobial peptides that together kill the entrapped microbes $[31,33]$. One of the proinflammatory stimuli known to strongly activate NET production is IL-8 [34, 35]. We found that human neutrophil exposure to the WT GAS parent strain resulted in a more than 3 -fold increase in NET production as compared with treatment with the $\Delta$ Pil mutant $(P<0.0001)$; NET induction was restored to near WT levels in the $\Delta$ Pil + Pil complemented mutant $(\mathrm{P}<0.0001$; Fig. 5a). Representative fluorescent microscopy images showing increased NET production (red arrows) by human neutrophils when infected with WT and $\triangle$ Pil+Pil GAS strains compared with infection with the $\triangle$ Pil mutant GAS are shown in Fig. 5b. Because GAS pilus expression induced IL- 8 production and NET release, and because pili represent projecting structures that increase the surface area of the bacterium, we hypothesized that piliated GAS would have greater adherence to NETs and suscep- tibility to NET killing. For equalization, neutrophils were stimulated with PMA prior to allow maximal NET production prior to GAS exposure. Significantly more WT GAS and $\triangle$ Pil+Pil complemented mutant GAS adhered to NETs than did $\triangle$ Pil mutant GAS $(P<0.003$; Fig. $5 \mathrm{c})$. Representative images of FITC-labeled GAS entrapped within NETs, shown in Fig. 5d, demonstrate increased entrapment of WT and $\triangle$ Pil+Pil GAS compared with the $\Delta$ Pil mutant. Correspondingly, killing of GAS within the induced NETs was significantly greater for WT GAS (78\% of inoculum) and $\triangle$ Pil+Pil complemented mutant GAS (99\%) than the $\Delta$ Pil mutant strain $(55 \% ; P<0.05$; Fig. 5 e). Thus, we conclude that pilus expression enhances neutrophil extracellular clearance of GAS, through induction of IL-8, activation of NET formation, and enhanced entrapment of the bacterium within these structures.

\section{Discussion}

Through more than 50 years of research, the presence of long, pilus-like polymers extending from the surface of pathogenic streptococci went unrecognized. Now, a few years after genome analyses inspired their discovery $[9,13$, 36], streptococcal pili are appreciated to influence host cell adherence, biofilm formation, interactions with the innate immune system, and virulence potential $[9-11,15,17,18$, 37-39]. In the present study, we use targeted mutagenesis to examine the role of the major pilus subunit of GAS, now recognized to represent the classical $\mathrm{T}$ antigen of this species, in virulence phenotypes of the globally disseminated M1T1 clone that is the leading agent of pharyngitis and invasive infections. While extending the tissue culture results to demonstrate that GAS pili enhance adherence to intact mouse skin, we find a surprising negative effect of pili on invasive disease potential, which contrasts the established virulence role of GBS and pneumococcal pili in similar mouse models. Thus, the functional roles of pili in streptococcal pathogenesis are not universal, but rather bear important species-specific attributes, such that generalizations should not be assumed. Although similarities are identified in the general genomic structure of streptococcal pilus gene loci, including the presence of sortases for covalent linkage of LP(X)TG sequence motifs in the major pilus subunits, significant sequence diversity in the pilus genes themselves would appear to allow for functional diversity of the encoded proteins [8].

A validated model for development of invasive M1T1 GAS infection shows that innate immune-mediated selection of mutations in the $\operatorname{cov} \mathrm{R} / \mathrm{S}$ two-component regulator are a critical step in systemic dissemination of the pathogen [40-44]. Such mutations lead to upregulation of key M1T1 GAS virulence factors that promote resistance to neutrophil 

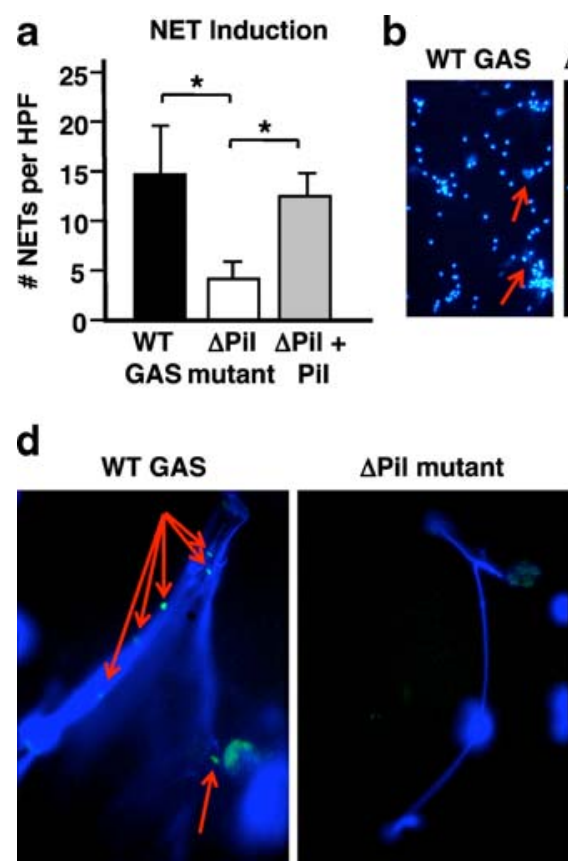

Fig. 5 GAS pilus expression stimulates neutrophil extracellular trap $(N E T)$ release and increases GAS entrapment and killing within NETs. a WT GAS (3.6 fold) and $\triangle$ Pil + Pil complemented mutant (3.0 fold) induce more NETs than the $\triangle$ Pil mutant $(P<0.0001)$. b Representative fluoresencent microscopic images of NETs (red arrows) induced by WT GAS, $\Delta$ Pil mutant, $\Delta$ Pil + Pil complemented mutant strains and $\mathbf{c}$ WT

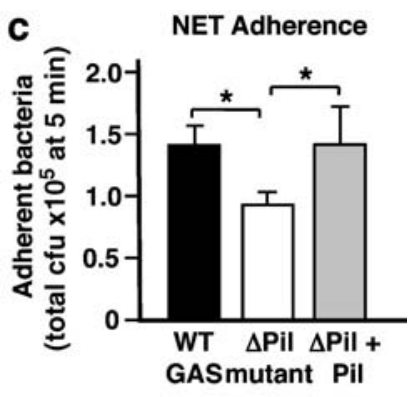

e

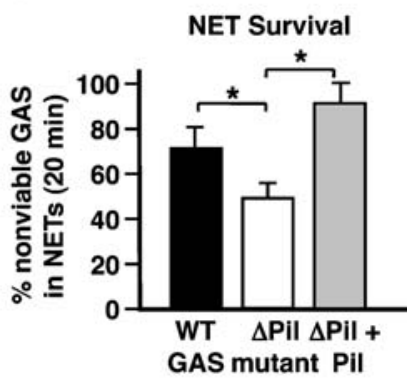

defenses, while allowing accumulation and activation of host plasminogen on the bacterial surface, promoting tissue spreading $[42,44]$. Upon in vivo selection, two of the most strongly upregulated GAS M1T1 genes, the IL-8 peptidase SpyCEP and the phage-encoded DNAse Sda1, promote resistance to NET-mediated killing, by blocking IL-8 stimulation of NET production and by degrading the DNA backbone of NETs, respectively [23, 35, 45]. Here we identify GAS M1T1 pilus expression as instead promoting susceptibility to NET-mediated killing, likely through increased IL-8-dependent NET production coupled with increased adherence to and physical entrapment within the generated NETs. The GAS M1T1 pilus thus plays an important role in virulence during establishment of infection by increasing epithelial adherence, but may simultaneously represent a pathogen-associated molecular pattern recognized by phagocytes, promoting increased killing of GAS upon arrival in blood or deeper tissues. Transcriptional analysis indicates the M1T1 GAS spy1028 major pilus subunit gene is slightly downregulated (by 1.2 fold) upon the in vivo selected $\operatorname{cov} \mathrm{R} / \mathrm{S}$ mutations [40], which would reduce its contributions to NET generation and entrapment just as the above-mentioned NET-resistance genes are upregulated.

The observed activation of host cytokine release for GAS M1T1 was also reported for the pneumococcal pilus [9]; Similarly, the P pili or type I pili of uropathogenic
GAS and $\triangle \mathrm{Pil}+\mathrm{Pil}$ complemented mutant strains are entrapped to a greater extent than the $\Delta$ Pil mutant $(P=0.0001$ and 0.003 , respectively). d Representative images of FITC-labeled GAS adherent to NETs, with red arrows highlighting the green bacteria adherent to blue NETs. e WT GAS $(P=0.03)$ and the $\Delta$ Pil + Pil complemented mutant $(P=0.006)$ are killed to a greater extent within NETs than the $\Delta$ Pil mutant
Escherichia coli have been shown to stimulate IL-8 release and induce migration of neutrophils across cellular barriers [46, 47]. As we observed for the M1T1 GAS pilus, the surface expressed GAS M1 protein was recently recognized to stimulate NET production [48, 49], but M1 nevertheless promotes GAS survival within these structures because it reduces the bacterium's susceptibility to human and murine cathelicidin antimicrobial peptides present in NETs [48]. In contrast, the GAS pilus was not observed to promote cathelicidin resistance, a feature reported for pili of certain strains of GBS [11].

Finally, though impeding invasive infection, our data confirm that pilus expression is important for M1T1 GAS adherence to human keratinocytes in vitro, as previously reported [17], and we show that this phenotype is robust enough to promote bacterial adherence to intact mouse skin. Similarly, our finding that pili promote adherence to human HEp-2 pharyngeal epithelial cells supports binding studies performed with tonsillar explants [17]. Because of the documented immunogenicity of the GAS pilus ( $\mathrm{T}$ antigen) in natural infection and mouse vaccination studies [13, 15], the major pilus subunit Spy1028 continues to represent an outstanding candidate GAS vaccine antigen, with the potential to inhibit GAS colonization of the two major epithelial surfaces (skin and pharynx) where it is normally resident. 
Acknowledgements This work was supported by NIH grant AI077780 to V.N. L.E.C.A. received a fellowship from The Hartwell Foundation. S.H.M.R. was supported by a grant from the European Molecular Biology Organization, H.C.M. by a National Science Foundation (NSF) Graduate Research Fellowship, A.M.T. by an A.P. Giannini Foundation Postdoctoral Fellowship and M.v.K.-B. through a fellowship from the Deutsche Akademie der Naturforscher Leopoldina (BMBF-LPD 9901/8-187). We thank Anna Cogen for sharing protocols for bacterial adherence to mouse skin.

Conflicts of interest The authors declare that they have no conflicts of interest.

Open Access This article is distributed under the terms of the Creative Commons Attribution Noncommercial License which permits any noncommercial use, distribution, and reproduction in any medium, provided the original author(s) and source are credited.

\section{References}

1. Carapetis JR, Steer AC, Mulholland EK, Weber M (2005) The global burden of group A streptococcal diseases. Lancet Infect Dis 5:685-694

2. Steer AC, Danchin MH, Carapetis JR (2007) Group A streptococcal infections in children. J Paediatr Child Health 43:203-213

3. Lamagni TL, Darenberg J, Luca-Harari B, Siljander T, Efstratiou A, Henriques-Normark B, Vuopio-Varkila J, Bouvet A, Creti R, Ekelund K, Koliou M, Reinert RR, Stathi A, Strakova L, Ungureanu V, Schalen C, Jasir A (2008) Epidemiology of severe Streptococcus pyogenes disease in Europe. J Clin Microbiol 46:2359-2367

4. Aziz RK, Kotb M (2008) Rise and persistence of global M1T1 clone of Streptococcus pyogenes. Emerg Infect Dis 14:1511-1517

5. Cleary PP, Kaplan EL, Handley JP, Wlazlo A, Kim MH, Hauser AR, Schlievert PM (1992) Clonal basis for resurgence of serious Streptococcus pyogenes disease in the 1980s. Lancet 339:518-521

6. Cunningham MW (2000) Pathogenesis of group A streptococcal infections. Clin Microbiol Rev 13:470-511

7. Kwinn LA, Nizet V (2007) How group A Streptococcus circumvents host phagocyte defenses. Future Microbiol 2:75-84

8. Telford JL, Barocchi MA, Margarit I, Rappuoli R, Grandi G (2006) Pili in gram-positive pathogens. Nat Rev Microbiol 4:509-519

9. Barocchi MA, Ries J, Zogaj X, Hemsley C, Albiger B, Kanth A, Dahlberg S, Fernebro J, Moschioni M, Masignani V, Hultenby K, Taddei AR, Beiter K, Wartha F, von Euler A, Covacci A, Holden DW, Normark S, Rappuoli R, Henriques-Normark B (2006) A pneumococcal pilus influences virulence and host inflammatory responses. Proc Natl Acad Sci U S A 103:2857-2862

10. Maisey HC, Hensler M, Nizet V, Doran KS (2007) Group B streptococcal pilus proteins contribute to adherence to and invasion of brain microvascular endothelial cells. J Bacteriol 189:1464-1467

11. Maisey HC, Quach D, Hensler ME, Liu GY, Gallo RL, Nizet V, Doran KS (2008) A group B streptococcal pilus protein promotes phagocyte resistance and systemic virulence. FASEB J 22:1715-1724

12. Kreikemeyer B, Nakata M, Oehmcke S, Gschwendtner C, Normann J, Podbielski A (2005) Streptococcus pyogenes collagen type I-binding Cpa surface protein. Expression profile, binding characteristics, biological functions, and potential clinical impact. J Biol Chem 280:33228-33239

13. Mora M, Bensi G, Capo S, Falugi F, Zingaretti C, Manetti AG, Maggi T, Taddei AR, Grandi G, Telford JL (2005) Group A Streptococcus produce pilus-like structures containing protective antigens and Lancefield T antigens. Proc Natl Acad Sci U S A 102:15641-15646

14. Lancefield RC, Dole VP (1946) The properties of T antigens extracted from group A hemolytic streptococci. J Exp Med 84:449-471

15. Manetti AG, Zingaretti C, Falugi F, Capo S, Bombaci M, Bagnoli F, Gambellini G, Bensi G, Mora M, Edwards AM, Musser JM, Graviss EA, Telford JL, Grandi G, Margarit I (2007) Streptococcus pyogenes pili promote pharyngeal cell adhesion and biofilm formation. Mol Microbiol 64:968-983

16. Edwards AM, Manetti AG, Falugi F, Zingaretti C, Capo S, Buccato S, Bensi G, Telford JL, Margarit I, Grandi G (2008) Scavenger receptor gp340 aggregates group A streptococci by binding pili. Mol Microbiol 68:1378-1394

17. Abbot EL, Smith WD, Siou GP, Chiriboga C, Smith RJ, Wilson JA, Hirst BH, Kehoe MA (2007) Pili mediate specific adhesion of Streptococcus pyogenes to human tonsil and skin. Cell Microbiol 9:1822-1833

18. Lizano S, Luo F, Bessen DE (2007) Role of streptococcal T antigens in superficial skin infection. J Bacteriol 189:1426-1434

19. Chatellier S, Ihendyane N, Kansal RG, Khambaty F, Basma H, Norrby-Teglund A, Low DE, McGeer A, Kotb M (2000) Genetic relatedness and superantigen expression in group A streptococcus serotype M1 isolates from patients with severe and non-severe invasive diseases. Infect Immun 68:3523-3534

20. Jeng A, Sakota V, Li Z, Datta V, Beall B, Nizet V (2003) Molecular genetic analysis of a group A Streptococcus operon encoding serum opacity factor and a novel fibronectin-binding protein, SfbX. J Bacteriol 185:1208-1217

21. Timmer AM, Kristian SA, Datta V, Jeng A, Gillen CM, Walker MJ, Beall B, Nizet V (2006) Serum opacity factor promotes group A streptococcal epithelial cell invasion and virulence. Mol Microbiol 62:15-25

22. Datta V, Myskowski SM, Kwinn LA, Chiem DN, Varki N, Kansal RG, Kotb M, Nizet V (2005) Mutational analysis of the group A streptococcal operon encoding streptolysin $\mathrm{S}$ and its virulence role in invasive infection. Mol Microbiol 56:681-695

23. Buchanan JT, Simpson AJ, Aziz RK, Liu GY, Kristian SA, Kotb M, Feramisco J, Nizet V (2006) DNase expression allows the pathogen group A Streptococcus to escape killing in neutrophil extracellular traps. Curr Biol 16:396-400

24. Goldmann O, Rohde M, Chhatwal GS, Medina E (2004) Role of macrophages in host resistance to group A streptococci. Infect Immun 72:2956-2963

25. Kunkel SL, Standiford T, Kasahara K, Strieter RM (1991) Interleukin-8 (IL-8): the major neutrophil chemotactic factor in the lung. Exper Lung Res 17:17-23

26. Bazzoni F, Cassatella MA, Rossi F, Ceska M, Dewald B, Baggiolini M (1991) Phagocytosing neutrophils produce and release high amounts of the neutrophil-activating peptide 1/interleukin 8. J Exp Med 173:771-774

27. Strieter RM, Kasahara K, Allen RM, Standiford TJ, Rolfe MW, Becker FS, Chensue SW, Kunkel SL (1992) Cytokine-induced neutrophil-derived interleukin-8. Amer J Path 141:397-407

28. Simms HH, D’Amico R (1997) Studies on polymorphonuclear leukocyte bactericidal function: the role of exogenous cytokines. Shock 7:84-89

29. Thelen M, Peveri P, Kernen P, von Tscharner V, Walz A, Baggiolini M (1988) Mechanism of neutrophil activation by NAF, a novel monocyte-derived peptide agonist. FASEB J 2:2702-2706

30. Brinkmann V, Reichard U, Goosmann C, Fauler B, Uhlemann Y, Weiss DS, Weinrauch Y, Zychlinsky A (2004) Neutrophil extracellular traps kill bacteria. Science 303:1532-1535

31. von Köckritz-Blickwede M, Nizet V (2009) Innate immunity turned inside-out: antimicrobial defense by phagocyte extracellular traps. J Mol Med 87:775-783 
32. Wartha F, Henriques-Normark B (2008) ETosis: a novel cell death pathway. Sci Signal 1:pe25

33. Fuchs TA, Abed U, Goosmann C, Hurwitz R, Schulze I, Wahn V, Weinrauch Y, Brinkmann V, Zychlinsky A (2007) Novel cell death program leads to neutrophil extracellular traps. J Cell Biol 176:231-241

34. Gupta AK, Hasler P, Holzgreve W, Gebhardt S, Hahn S (2005) Induction of neutrophil extracellular DNA lattices by placental microparticles and IL-8 and their presence in preeclampsia. Human Immunol 66:1146-1154

35. Zinkernagel AS, Timmer AM, Pence MA, Locke JB, Buchanan JT, Turner CE, Mishalian I, Sriskandan S, Hanski E, Nizet V (2008) The IL-8 protease SpyCEP/ScpC of group A Streptococcus promotes resistance to neutrophil killing. Cell Host Microbe 4:170-178

36. Lauer P, Rinaudo CD, Soriani M, Margarit I, Maione D, Rosini R, Taddei AR, Mora M, Rappuoli R, Grandi G, Telford JL (2005) Genome analysis reveals pili in Group B Streptococcus. Science 309:105

37. Dramsi S, Caliot E, Bonne I, Guadagnini S, Prevost MC, Kojadinovic M, Lalioui L, Poyart C, Trieu-Cuot P (2006) Assembly and role of pili in group B streptococci. Mol Microbiol 60:14011413

38. Krishnan V, Gaspar AH, Ye N, Mandlik A, Ton-That H, Narayana SV (2007) An IgG-like domain in the minor pilin GBS52 of Streptococcus agalactiae mediates lung epithelial cell adhesion. Structure 15:893-903

39. Konto-Ghiorghi Y, Mairey E, Mallet A, Dumenil G, Caliot E, Trieu-Cuot P, Dramsi S (2009) Dual role for pilus in adherence to epithelial cells and biofilm formation in Streptococcus agalactiae. PLoS Pathog 5:e1000422

40. Sumby P, Whitney AR, Graviss EA, DeLeo FR, Musser JM (2006) Genome-wide analysis of group a streptococci reveals a mutation that modulates global phenotype and disease specificity. PLoS Pathog 2:e5

41. Cole JN, McArthur JD, McKay FC, Sanderson-Smith ML, Cork AJ, Ranson M, Rohde M, Itzek A, Sun H, Ginsburg D, Kotb M,
Nizet V, Chhatwal GS, Walker MJ (2006) Trigger for group A streptococcal M1T1 invasive disease. FASEB J 20:1745-1747

42. Walker MJ, Hollands A, Sanderson-Smith ML, Cole JN, Kirk JK, Henningham A, McArthur JD, Dinkla K, Aziz RK, Kansal RG, Simpson AJ, Buchanan JT, Chhatwal GS, Kotb M, Nizet V (2007) DNase Sda1 provides selection pressure for a switch to invasive group A streptococcal infection. Nat Med 13:981985

43. Trevino J, Perez N, Ramirez-Pena E, Liu Z, Shelburne SA 3rd, Musser JM, Sumby P (2009) CovS simultaneously activates and inhibits the CovR-mediated repression of distinct subsets of group A Streptococcus virulence factor-encoding genes. Infect Immun 77:3141-3149

44. Musser JM, Shelburne SA 3rd (2009) A decade of molecular pathogenomic analysis of group A Streptococcus. J Clin Invest 119:2455-2463

45. Sumby P, Barbian KD, Gardner DJ, Whitney AR, Welty DM, Long RD, Bailey JR, Parnell MJ, Hoe NP, Adams GG, Deleo FR, Musser JM (2005) Extracellular deoxyribonuclease made by group A Streptococcus assists pathogenesis by enhancing evasion of the innate immune response. Proc Natl Acad Sci U S A 102:1679-1684

46. Sauer FG, Mulvey MA, Schilling JD, Martinez JJ, Hultgren SJ (2000) Bacterial pili: molecular mechanisms of pathogenesis. Curr Opin Microbiol 3:65-72

47. Godaly G, Otto G, Burdick MD, Strieter RM, Svanborg C (2007) Fimbrial lectins influence the chemokine repertoire in the urinary tract mucosa. Kidney Int 71:778-786

48. Lauth X, von Köckritz-Blickwede M, McNamara CW, Myskowski S, Zinkernagel AS, Beall B, Ghosh P, Gallo RL, Nizet V (2009) M1 protein allows group A streptococcal survival in phagocyte extracellular traps through cathelicidin inhibition. J Innate Immun $1: 202-214$

49. Oehmcke S, Mörgelin M, Herwald H (2009) Activation of the human contact system on neutrophil extracellular traps. J Innate Immun 1:225-230 